\title{
Article \\ Identification of Aquaporin Gene Family in Response to Natural Cold Stress in Ligustrum $\times$ vicaryi Rehd.
}

\author{
Jiahui Dong ${ }^{1,+}$, Shance Niu ${ }^{1,+} \mathbb{\oplus}$, Ji Qian ${ }^{1,+}+\mathbb{C}$, Juan Zhou ${ }^{2}$, Mengnan Zhao ${ }^{1}$, Yu Meng ${ }^{3}$ and Bao Di ${ }^{1, * \mathbb{C}}$ \\ 1 College of Horticulture, Hebei Agriculture University, Baoding 071000, China; djh285170105@126.com (J.D.); \\ niushance@163.com (S.N.); qianji167@163.com (J.Q.); zhaomengnan526@163.com (M.Z.) \\ 2 College of Mechanical and Electric Engineering, Hebei Agriculture University, Baoding 071000, China; \\ zhoujuan1129@163.com \\ 3 College of Landscape and Tourism, Hebei Agriculture University, Baoding 071000, China; \\ my131sohu@126.com \\ * Correspondence: dibao666@126.com; Tel.: +86-312-7528313 \\ + These authors contributed equally to this work.
}

Citation: Dong, J.; Niu, S.; Qian, J.; Zhou, J.; Zhao, M.; Meng, Y.; Di, B. Identification of Aquaporin Gene Family in Response to Natural Cold Stress in Ligustrum $\times$ vicaryi Rehd. Forests 2022, 13, 182. https:// doi.org/10.3390/f13020182

Academic Editor: Yuepeng Song and Carol A. Loopstra

Received: 9 December 2021

Accepted: 24 January 2022

Published: 26 January 2022

Publisher's Note: MDPI stays neutral with regard to jurisdictional claims in published maps and institutional affiliations.

Copyright: (C) 2022 by the authors. Licensee MDPI, Basel, Switzerland. This article is an open access article distributed under the terms and conditions of the Creative Commons Attribution (CC BY) license (https:// creativecommons.org/licenses/by/ $4.0 /)$.

\begin{abstract}
Plants are susceptible to a variety of abiotic stresses during the growing period, among which low temperature is one of the more frequent stress factors. Maintaining water balance under cold stress is a difficult and critical challenge for plants. Studies have shown that aquaporins located on the cytomembrane play an important role in controlling water homeostasis under cold stress, and are involved in the tolerance mechanism of plant cells to cold stress. In addition, the aquaporin gene family is closely related to the cold resistance of plants. As a major greening tree species in urban landscaping, Ligustrum $\times$ vicaryi Rehd. is more likely to be harmed by low temperature after a harsh winter and a spring with fluctuating temperatures. Screening the target aquaporin genes of Ligustrum $\times$ vicaryi responding to cold resistance under natural cold stress will provide a scientific theoretical basis for cold resistance breeding of Ligustrum $\times$ vicaryi. In this study, the genome-wide identification of the aquaporin gene family was performed at four different overwintering periods in September, November, January and April, and finally, 58 candidate Ligustrum $\times$ vicaryi aquaporin (LvAQP) genes were identified. The phylogenetic analysis revealed four subfamilies of the LvAQP gene family: 32 PIPs, 11 TIPs, 11 NIPs and 4 SIPs. The number of genes in PIPs subfamily was more than that in other plants. Through the analysis of aquaporin genes related to cold stress in other plants and LvAQP gene expression patterns identified 20 LvAQP genes in response to cold stress, and most of them belonged to the PIPs subfamily. The significantly upregulated LvAQP gene was Cluster-9981.114831, and the significantly downregulated LvAQP genes were Cluster-9981.112839, Cluster-9981.107281, and Cluster-9981.112777. These genes might play a key role in responding to cold tolerance in the natural low-temperature growth stage of Ligustrum $\times$ vicaryi.
\end{abstract}

Keywords: Ligustrum $\times$ vicaryi Rehd; aquaporin; natural cold stress; cold resistance

\section{Introduction}

Aquaporin is a protein located on the cytomembrane that controls the entry and exit of water in cells. Water uptake, transport across membranes and tissues are essential for plants growth and development, and the transmembrane transport of water molecules is mainly regulated by aquaporins. In biological membranes, plant aquaporins have a highly conserved Asn-Pro-Ala (NPA) motif structure, which plays a crucial role in the formation of water-selective channels [1]. It has been reported that AEFXXT motif located in the first helix (TM1) in plant aquaporins is highly conserved in almost all major intrinsic proteins (MIPs), but the exact function of the AEFXXT motif is still unclear [2]. The previous studies based on genomic data revealed that aquaporins constitute a huge gene family in plants. These aquaporins are divided into five main subfamilies according to their amino acid sequence [3]: plasma membrane intrinsic proteins (PIPs), tonoplast intrinsic proteins 
(TIPs), nodulin26-like intrinsic proteins (NIPs), small basic intrinsic proteins (SIPs) and uncharacterized $X$ intrinsic proteins (XIPs). In recent research, there have been studies related to the identification and expression analysis of the whole aquaporin gene family in more than 20 plants, such as Arabidopsis thaliana [4], Oryza sativa [5], Zea mays [6], Hordeum vulgare [7], Glycine max [8], Gossypium hirsutum [9], Citrullus lanatus [10], Brassica rapa [11], and so on. However, a considerable number of studies have confirmed that it is a difficult but critical challenge for plants to maintain water balance under various adversities. Therefore, aquaporins have a great effect on maintaining water homeostasis in plants under different environmental stress [12-18].

Plants are susceptible to a variety of abiotic stresses during the growing period, especially cold stress $[19,20]$. Plants respond to cold stress by increasing root water absorption [21]. As an important regulator of water absorption and transport, aquaporins play a key role in regulating water balance in plants at low temperature. For instance, Azad et al. showed that temperature changes could induce AQP phosphorylation and dephosphorylation, thus affecting water transport [22]. Many studies have shown that aquaporins play a crucial role in resisting cold stress [23]. For instance, under cold stress, OsPIP 2;4 and OsPIP2;5 were abundantly expressed in the root system in order to enhance cold resistance in rice [24]. The OsPIP2;5 and OsPIP2;7 of Oryza sativa were engaged with rapid water transport and with maintaining water balance during the cold stress stage, which played a major role in regulating water channel opening under cold stress [25]. The overexpression of AtPIP1;4 or AtPIP2;5 in transgenic plants of Arabidopsis thaliana could improve water conductivity and promote germination [26]. The overexpression of TaTIP2;2 in transgenic plants of wheat could make plants grow normally under cold conditions as well [27]. Overexpressing or repressing expression of related aquaporin genes to enhance cold resistance of Oryza sativa [28], Hordeum vulgare [29], Musa acuminata [30-32], Populus trichocarpa [33], Sorghum bicolor [34], Triticum aestivum [35,36] and Brassica rapa [11] have been investigated under cold stress. Among these plants, 11, 11, 8, 6, 9, 2 and 8 AQP genes showed significant correlations with cold stress. Numerous studies have shown that the aquaporin gene family is closely related to the cold resistance of plants.

With golden yellow leaves, Ligustrum $\times$ vicaryi is widely used in China, the United States, and Canada along with Berberis thunbergii var. atropurpurea and Buxus megistophylla Levl., but it is susceptible to low temperature injury during the seedling stage [37]. In this study, we aimed to identify the Ligustrum $\times$ vicaryi aquaporin (LvAQP) gene family, and its expression pattern was analyzed, and the expression changes of the LvAQP gene family in different periods were investigated; the screened target aquaporin genes responded to cold resistance under natural low temperature stress. The results of this research will lay the foundation for further biological function verification of cold resistance-related aquaporin candidate genes in Ligustrum $\times$ vicaryi, especially in the PIPs subfamily, and they will provide a theoretical basis for improving seedling quality and breeding of Ligustrum $\times$ vicaryi.

\section{Materials and Methods}

\subsection{Plant Materials and Treatment}

One-year-old container seedlings of Ligustrum $\times$ vicaryi (txid1133299) were obtained from the Beijing Florascape Co., Ltd. (Beijing, China) $\left(40^{\circ} 11^{\prime} \mathrm{N}, 116^{\circ} 48^{\prime} \mathrm{E}\right)$. We obtained the permission to collect the plant samples from the Beijing Florascape Co., Ltd. (Beijing, China), and the plant materials were formally identified by senior engineer Ju Chen of the company and were later identified by professor Gang Zhang of Hebei Agricultural University. The Ligustrum $\times$ vicaryi were cultivated in Specimen Park $\left(38^{\circ} 50^{\prime} \mathrm{N}, 115^{\circ} 26^{\prime} \mathrm{E}\right)$ of Hebei Agricultural University, Baoding City, Hebei Province, in September 2019. In the experimental setup, the container seedlings were divided into three replicates for the measurements at each sampling time, with 25 plants in each replicate. The spacing within the row and the spacing between rows were $25 \times 50 \mathrm{~cm}$, which were consistent cultivation conditions and conventional maintenance management. 
The seedlings overwintered naturally in the open field. The seedlings were sampled on the 24th of each month in September and November 2019 and in January and April 2020.

\subsection{Determination of Cold Resistance of Ligustrum $\times$ vicaryi}

The seedlings were taken at four sampling times. The seedlings were placed in an artificial climate chamber for low temperature treatment using the method of Di [38] (Table 1). During the cooling period, the seedlings were kept at $-3{ }^{\circ} \mathrm{C}$ for $5 \mathrm{~h}$ to keep the soil and air temperature consistent and were then continued to cool at the same temperature. Each set target temperature was maintained for $4 \mathrm{~h}$. After that treatment, the seedlings were placed at $4{ }^{\circ} \mathrm{C}$ for 5 days and room temperature for 1 day, and the cold resistance of roots was measured by relative electrolyte leakage (REL).

Table 1. The temperatures for the measurement of cold hardiness after controlled freezing tests.

\begin{tabular}{clccccc}
\hline Date $(\mathbf{m})$ & \multicolumn{5}{c}{ Temperature/ ${ }^{\circ} \mathbf{C}$} \\
\hline September & 4 & -3 & -8 & -18 & -23 & -35 \\
November & 4 & -6 & -12 & -23 & -35 & -45 \\
January & 4 & -8 & -18 & -30 & -48 & -60 \\
April & 4 & -6 & -12 & -23 & -35 & -45 \\
\hline
\end{tabular}

\subsection{RNA-Seq}

\subsubsection{RNA Extraction and Detection}

The seedlings were taken at four sampling times. The roots of the plants were washed by tap water to remove the soil, and the fine roots were rinsed with tap water, distilled water and ultrapure water in turn (the water was placed in Specimen Park in advance and the temperature was kept consistent with the environment), and then they were frozen in liquid nitrogen and stored in an ultra-low temperature freezer at $-80{ }^{\circ} \mathrm{C}$.

Material was sequenced at Tianjin Novogene Biotechnology Co., Ltd., (Tianjin, China). Total RNA was extracted by Omniplant RNA Kit (DNase I).

The RNA integrity was detected by agarose gel electrophoresis with $2 \%$ concentration, $150 \mathrm{~V}, 150 \mathrm{~mA}$. The concentration of each RNA sample and its optical density in the wavelength range of 260 and $280 \mathrm{~nm}$ were measured by Nano Drop one spectrophotometer, and the $\mathrm{OD}_{260} / \mathrm{OD}_{280}$ value was calculated to detect the purity of RNA; then the RNA was stored in an ultra-low temperature freezer at $-80^{\circ} \mathrm{C}$.

\subsection{2. cDNA Library Construction}

First, magnetic beads with Oligo(dT) were used to enrich eukaryotic mRNA. Second, mRNA was broken into short fragments by adding fragmentation buffer. One-stranded cDNA was synthesized with six-base random hexamers using mRNA as a template. Third, double-stranded cDNA was formed by adding buffer, dNTPs, DNA polymerase I, and RNase H, which was purified by AMPure XP beads. The purified double-stranded cDNA was end-repaired and $\mathrm{dA}$-tailed to ligate to sequencing connectors, and then fragment size selection was performed with AMPure XP beads. Finally, polymerase chain reaction (PCR) amplification was conducted, and the PCR products were purified with AMPure XP beads to obtain the final cDNA library. After the completion of the cDNA library construction, the initial quantification was operationalized by using Qubit 2.0, and then the library was diluted. Subsequently, the insert size of the library was tested. When the insert size met the expectation, the effective concentration of the library was accurately quantified by the Q-PCR method (effective library concentration $>2 \mathrm{nM}$ ) to ensure the quality of the cDNA library.

\subsubsection{RNA Data Analysis}

The raw image data generated by the sequencer were transformed into raw data or raw reads by base calling. The results were stored in fastq format, which were part 
of the original file, including the sequence of reads and the sequencing quality of reads. Raw reads were processed to obtain clean reads by removing reads containing an adaptor, reads containing more than $10 \%$ of $\mathrm{N}$ and reads containing a small amount of low-quality sequences (the number of bases with quality value $\mathrm{Q}<5$ accounts for more than $50 \%$ of the entire reads).

The transcriptome data were assembled by Trinity v2.4.0 software with the following commands and parameters: Trinity—seq Type fq-max_memory 300G—left file_1. fq-right file_2.fq-CPU 50—full_clean up-KMER_SIZE 30-min_kmer_cov 5. Among the genes containing multiple transcripts, the sequence with the longest transcript was used as the basis for calculating expression, RSEM worked as the method for transcript abundance calculation, and trimmed mean of M-values (TMM) was used as the method for normalization between samples.

KEGG PATHWAY enrichment analysis on the results of variance analysis was performed by kobas software.

\subsection{Identification of LvAQP Gene Family}

Based on the transcriptome of Ligustrum $\times$ vicaryi and the study on the model plant Arabidopsis thaliana, the gene sequences of 35 Arabidopsis thaliana aquaporin genes (Table A1) were downloaded from NCBI (https: / / www.mhttps / / www.ncbi.nlm.nih.gov/, accessed on 2 June 2021). The transcriptome database of Ligustrum $\times$ vicaryi was searched by blast homology retrieval method, and the LvAQP gene family was identified. The LvAQP genes were screened by MAFFT comparison software and a manual correction process using CD-HIT Suite (http:/ / weizhong-lab.ucsd.edu/cdhit-web-server/cgi-bin/index.cgi?cmd= cd-hit-est, accessed on 10 June 2021) to remove redundancy. The screened LvAQP gene family protein sequences were analyzed for physicochemical properties such as number of amino acids, molecular weight, theoretical pI, aliphatic index and grand average of hydropathicity, using the online software ExPASy (https:/ / web.expasy.org/protparam/, accessed on 25 June 2021).

\subsection{Construction of Phylogenetic Tree}

Multiple sequence alignment of candidate genes was performed by MAFFT software's E-INS-I strategy with necessary manual corrections. MEGA and PhyML3.0 software were used to construct the phylogenetic tree, and iTOL online software (https://itol.embl.de/ upload.cgi, accessed on 24 July 2021) was used for phylogenetic tree beautification. The constructed phylogenetic tree was analyzed by Alrt detection method and WAG model.

\subsection{Conserved Motifs Analysis}

LvAQP gene family was extracted using the MEME tool (https://meme-suite.org/ meme/tools/meme, accessed on 26 July 2021), with the following parameters: motif sequences, sites, width, E-value for each motif.

\subsection{Gene Expression Profile Analysis}

The LvAQP gene family expression profile was constructed using $\mathrm{MeV}$ software. The candidate genes were initially selected by differential gene expression analysis between natural low temperature treatment and non-low temperature treatment. Combining the constructed phylogenetic tree of LvAQP genes and the known cold resistance aquaporin genes of other plants aimed to find the homologs of known cold resistance genes of other plants within Ligustrum $\times$ vicaryi.

\subsection{LvAQP Gene Family Quantitative Real-Time PCR Validation}

\subsubsection{RNA Extraction}

Refer to Section 2.3.1. for RNA extraction. 


\subsubsection{Reverse Transcription of RNA into cDNA}

The UEIris II RT-PCR System for First-Strand cDNA Synthesis (with dsDNase) reverse transcription kit was used as follows: The RNA was denatured thermally at $65{ }^{\circ} \mathrm{C}$ for $5 \mathrm{~min}$, immediately iced for more than $3 \mathrm{~min}$, and then the reaction system was prepared as $20 \mu \mathrm{L}$ of the reverse transcription system: $2 \mu \mathrm{L}$ total RNA, $4 \mu \mathrm{L}$ UEIris II RT MasterMix $(5 \times)$, $13 \mu \mathrm{L}$ RNase-free Water, $1 \mu \mathrm{L}$ dsDNase.

Reaction conditions: reverse transcription $37^{\circ} \mathrm{C}$ for $2 \mathrm{~min} ; 55^{\circ} \mathrm{C}$ for $10 \mathrm{~min} ; 85^{\circ} \mathrm{C}$ for $10 \mathrm{~s}$. After the reaction, it was stored at $-20{ }^{\circ} \mathrm{C}$.

\subsubsection{Design of Primers for Quantitative Real-Time qRT-PCR}

Nine LvAQP genes related to cold stress were selected for qRT-PCR. Primers were designed by Primer3 Plus and synthesized by Sangon Biotech Co., Ltd. (Shanghai, China), and Ligustrum $\times$ vicaryi LvEF-1 $\alpha$ was selected as an internal reference gene; the primer information is shown in Table S1.

\subsection{4. qRT-PCR Reaction System and Reaction Conditions}

According to the instructions of AugeGreen ${ }^{\mathrm{TM}}$ qPCR Master Mix reagent, Roche fluorescence quantitative PCR instrument lightcyc196 was used to detect the expression of target genes. Preparation of reaction solution for $20 \mu \mathrm{L}$ reaction system: $10 \mu \mathrm{L} 2 \times$ AugeGreen $^{\mathrm{TM}}$ Master Mix, $7 \mu \mathrm{L}$ ddH2O, $1 \mu \mathrm{L}$ Forward Primer, $1 \mu \mathrm{L}$ Reverse Primer, $1 \mu \mathrm{L}$ cDNA template. qRT-PCR reaction procedure was as follows: $95^{\circ} \mathrm{C}$ for $2 \mathrm{~min} ; 40$ cycles of $15 \mathrm{~s}$ at $95{ }^{\circ} \mathrm{C}$ and $60 \mathrm{~s}$ at $58^{\circ} \mathrm{C} ; 95^{\circ} \mathrm{C}$ for $10 \mathrm{~s} ; 65^{\circ} \mathrm{C}$ for $60 \mathrm{~s} ; 97^{\circ} \mathrm{C}$ for $1 \mathrm{~s}$.

The last step was to analyze the solubility curve of the amplification products to determine the specificity of the primers. There were 3 technical replicates and 3 biological replicates for each sample during qRT-PCR reactions. The results of qRT-PCR were calculated by the $2^{-\Delta \Delta C T}$ method to obtain gene expression.

\section{Results}

\subsection{Cold Resistance of Ligustrum $\times$ vicaryi during Natural Cold Stress Period}

During the overwintering period, the cold resistance ability of Ligustrum $\times$ vicaryi gradually increased with the change of temperature in the early overwintering period, and gradually decreased in the late overwintering period (Figure 1). The strongest cold resistance appeared in January, reaching $-22.1^{\circ} \mathrm{C}$ and $11.4^{\circ} \mathrm{C}$ higher than that in September $\left(-10.7^{\circ} \mathrm{C}\right)$. The cold resistance in November was $-15.2^{\circ} \mathrm{C}$, and the cold resistance in April was $-13.0^{\circ} \mathrm{C}$, which was close to that in September.

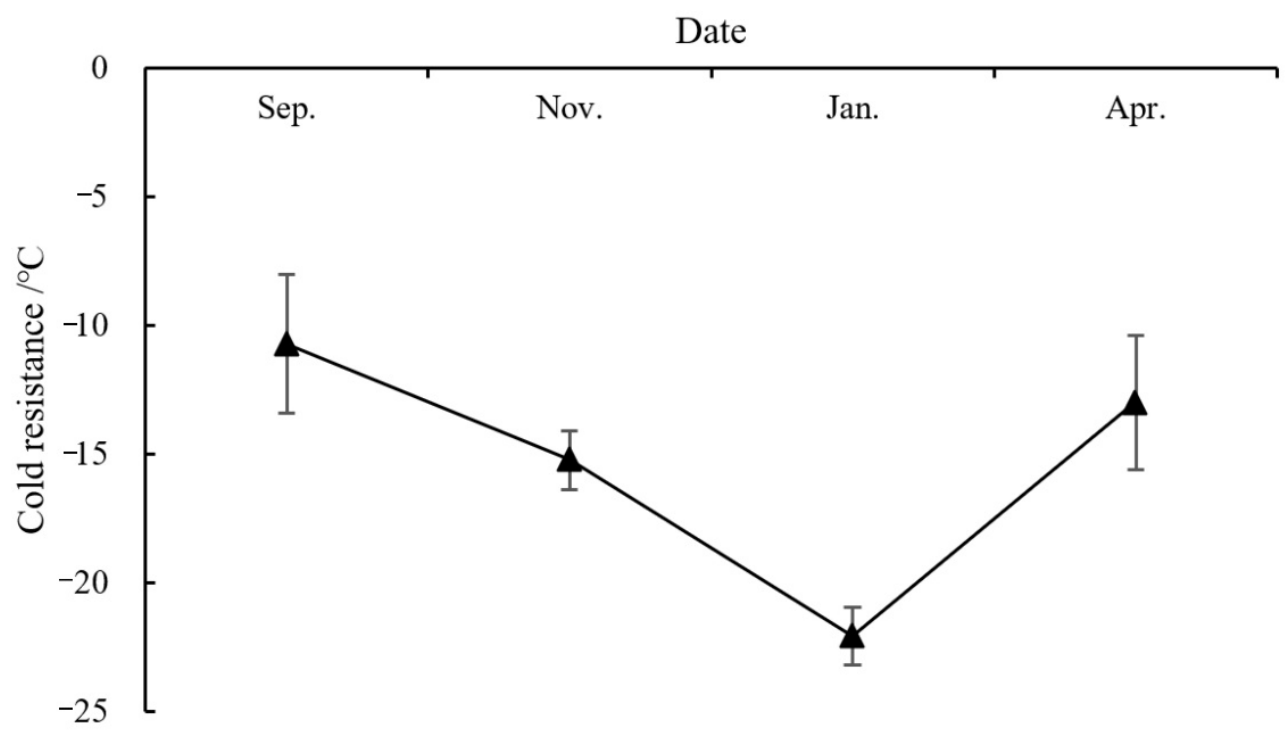

Figure 1. The cold hardiness in root of Ligustrum $\times$ vicaryi by REL during a natural cold stress period. 


\subsection{LvAQP Gene Family Identification}

Based on the Arabidopsis thaliana aquaporin gene family (Table A1), 58 candidate LvAQP genes were identified (Table 2). According to sequence alignment, the correlation of characteristic proteins and phylogenetic relationship, the $58 \mathrm{LvAQP}$ genes were classified into four subfamilies: PIPs, TIPs, NIPs and SIPs, which contained 32, 11, 11 and 4 genes, respectively. The results of the analysis of the physicochemical properties of the LvAQP gene family proteins (Table 2) showed that there were differences in the number of amino acids, molecular weight, theoretical pI, aliphatic index and grand average of hydropathicity of LvAQP gene family proteins. The number of amino acids in the protein sequence of the LvAQP gene family was 137-341. The molecular weight of the LvAQP gene family protein sequence was $13986.15-36029.94 \mathrm{Da}$. The theoretical pI of the LvAQP gene family protein sequences ranged from 5.34-9.91, and 40 of the 58 LvAQP proteins had a theoretical $\mathrm{pI}$ of greater than 7.5, indicating that most of the LvAQP gene family proteins are basic proteins. The aliphatic index of the LvAQP gene family protein sequences ranged from 89.25-116.37. The grand average of hydropathicity of the LvAQP gene family proteins was positive, revealing that they were hydrophobic proteins.

Table 2. Physicochemical properties of LvAQP gene family in Ligustrum $\times$ vicaryi.

\begin{tabular}{|c|c|c|c|c|c|c|}
\hline Subfamily & Gene Name & $\begin{array}{c}\text { Number of } \\
\text { Amino Acids (aa) }\end{array}$ & $\begin{array}{c}\text { Molecular } \\
\text { Weight (Da) }\end{array}$ & Theoretical pI & $\begin{array}{l}\text { Aliphatic } \\
\text { Index }\end{array}$ & $\begin{array}{c}\text { Grand Average of } \\
\text { Hydropathicity }\end{array}$ \\
\hline \multirow{32}{*}{ PIP } & Cluster-9981.112265 & 262 & $27,966.27$ & 7.22 & 91.26 & 0.255 \\
\hline & Cluster-9981.115068 & 298 & $32,266.44$ & 9.33 & 93.05 & 0.237 \\
\hline & Cluster-9981.109600 & 289 & $31,046.09$ & 8.60 & 95.57 & 0.348 \\
\hline & Cluster-9981.29850 & 308 & $32,910.19$ & 9.43 & 91.66 & 0.332 \\
\hline & Cluster-19966.0 & 308 & $32,956.20$ & 9.32 & 91.62 & 0.307 \\
\hline & Cluster-19036.0 & 311 & $32,859.87$ & 7.20 & 95.08 & 0.341 \\
\hline & Cluster-9981.112839 & 268 & $28,664.31$ & 9.34 & 89.25 & 0.204 \\
\hline & Cluster-9981.117133 & 278 & $30,018.76$ & 9.14 & 93.74 & 0.188 \\
\hline & Cluster-9981.29849 & 299 & $31,461.40$ & 8.32 & 100.94 & 0.510 \\
\hline & Cluster-9981.21661 & 300 & $32,170.31$ & 7.30 & 101.20 & 0.512 \\
\hline & Cluster-9981.200292 & 299 & $31,419.32$ & 8.32 & 99.97 & 0.503 \\
\hline & Cluster-9981.111171 & 306 & $32,894.05$ & 6.48 & 101.73 & 0.414 \\
\hline & Cluster-9981.109034 & 321 & $34,345.95$ & 8.51 & 103.40 & 0.451 \\
\hline & Cluster-9981.89369 & 290 & $30,949.85$ & 8.25 & 96.55 & 0.461 \\
\hline & Cluster-9981.170229 & 290 & $30,804.69$ & 7.84 & 98.28 & 0.494 \\
\hline & Cluster-9981.689 & 287 & $30,215.31$ & 9.46 & 101.74 & 0.516 \\
\hline & Cluster-9981.690 & 289 & $30,357.47$ & 9.46 & 101.73 & 0.525 \\
\hline & Cluster-9981.110451 & 301 & $32,265.67$ & 9.05 & 106.05 & 0.487 \\
\hline & Cluster-9981.198491 & 321 & $34,046.79$ & 9.66 & 101.93 & 0.428 \\
\hline & Cluster-9981.691 & 319 & $33,904.63$ & 9.66 & 101.94 & 0.419 \\
\hline & Cluster-9981.154931 & 288 & $30,489.49$ & 8.94 & 96.98 & 0.476 \\
\hline & Cluster-9981.154932 & 290 & $30,758.77$ & 8.94 & 95.97 & 0.503 \\
\hline & Cluster-9981.114832 & 307 & $33,106.57$ & 9.24 & 100.75 & 0.255 \\
\hline & Cluster-9981.114831 & 286 & $30,393.47$ & 8.81 & 104.76 & 0.492 \\
\hline & Cluster-9981.47893 & 286 & $30,590.74$ & 9.36 & 99.65 & 0.513 \\
\hline & Cluster-9981.47892 & 288 & $30,860.03$ & 9.36 & 98.61 & 0.540 \\
\hline & Cluster-9981.111170 & 279 & $30,122.78$ & 5.76 & 99.28 & 0.379 \\
\hline & Cluster-9981.21660 & 182 & $19,444.61$ & 9.33 & 101.37 & 0.513 \\
\hline & Cluster-9981.118516 & 276 & $30,359.41$ & 8.44 & 101.81 & 0.446 \\
\hline & Cluster-9981.107281 & 190 & $20,225.65$ & 9.75 & 99.16 & 0.581 \\
\hline & Cluster-48310.0 & 200 & $21,799.73$ & 9.91 & 99.50 & 0.405 \\
\hline & Cluster-9981.86061 & 148 & $15,695.98$ & 9.43 & 92.43 & 0.336 \\
\hline \multirow{11}{*}{$\mathrm{TIP}$} & Cluster-9981.112777 & 262 & $27,264.72$ & 5.66 & 110.27 & 0.822 \\
\hline & Cluster-9981.35612 & 268 & $28,185.59$ & 7.22 & 100.11 & 0.691 \\
\hline & Cluster-9981.111753 & 267 & $27,893.40$ & 6.41 & 103.82 & 0.742 \\
\hline & Cluster-9981.115801 & 254 & $26,223.37$ & 5.57 & 104.96 & 0.772 \\
\hline & Cluster-24993.0 & 252 & $25,967.19$ & 6.49 & 107.26 & 0.779 \\
\hline & Cluster-9981.112790 & 263 & $27,555.92$ & 5.36 & 107.98 & 0.835 \\
\hline & Cluster-9981.112789 & 261 & $26,692.22$ & 6.05 & 115.17 & 0.970 \\
\hline & Cluster-20432.0 & 250 & $25,340.33$ & 5.34 & 105.40 & 0.881 \\
\hline & Cluster-9981.122691 & 234 & $23,815.83$ & 5.79 & 116.37 & 0.918 \\
\hline & Cluster-9981.172823 & 262 & $27,677.53$ & 6.39 & 111.64 & 0.719 \\
\hline & Cluster-9981.111196 & 137 & $13,986.15$ & 6.68 & 96.93 & 0.596 \\
\hline
\end{tabular}


Table 2. Cont.

\begin{tabular}{|c|c|c|c|c|c|c|}
\hline Subfamily & Gene Name & $\begin{array}{c}\text { Number of } \\
\text { Amino Acids (aa) }\end{array}$ & $\begin{array}{c}\text { Molecular } \\
\text { Weight (Da) }\end{array}$ & Theoretical pI & $\begin{array}{l}\text { Aliphatic } \\
\text { Index }\end{array}$ & $\begin{array}{c}\text { Grand Average of } \\
\text { Hydropathicity }\end{array}$ \\
\hline \multirow{11}{*}{$\mathrm{NIP}$} & Cluster-9981.78169 & 290 & $30,914.92$ & 9.43 & 104.55 & 0.423 \\
\hline & Cluster-9981.133629 & 316 & $33,888.57$ & 9.34 & 104.02 & 0.450 \\
\hline & Cluster-9981.133630 & 320 & $34,289.04$ & 9.34 & 105.16 & 0.463 \\
\hline & Cluster-51933.0 & 291 & $30,748.42$ & 6.71 & 100.52 & 0.463 \\
\hline & Cluster-9981.178700 & 240 & $25,532.72$ & 7.84 & 107.21 & 0.555 \\
\hline & Cluster-36924.0 & 250 & $26,540.04$ & 8.83 & 107.24 & 0.667 \\
\hline & Cluster-9981.104986 & 341 & $36,029.94$ & 9.51 & 94.13 & 0.332 \\
\hline & Cluster-9981.123071 & 308 & $31,953.21$ & 9.53 & 98.90 & 0.378 \\
\hline & Cluster-9981.97911 & 284 & $30,038.99$ & 8.34 & 99.61 & 0.544 \\
\hline & Cluster-28512.0 & 285 & $30,427.38$ & 6.57 & 113.68 & 0.472 \\
\hline & Cluster-9981.54345 & 159 & $16,867.60$ & 9.89 & 107.92 & 0.487 \\
\hline \multirow{4}{*}{ SIP } & Cluster-9981.120365 & 245 & $25,817.37$ & 8.46 & 105.59 & 0.790 \\
\hline & Cluster-9981.105938 & 142 & $15,367.01$ & 9.14 & 95.56 & 0.411 \\
\hline & Cluster-9981.88037 & 286 & $31,510.94$ & 9.54 & 97.48 & 0.234 \\
\hline & Cluster-9981.88036 & 155 & $16,945.07$ & 9.47 & 103.81 & 0.405 \\
\hline
\end{tabular}

\subsection{Phylogenetic Analysis of LvAQP Gene Family}

By constructing phylogenetic tree, the distribution and development of the 58 candidate aquaporin genes of the four subfamilies of the LvAQP gene family can be known (Figure 2). The internal genes of the PIPs subfamily were more similar than that of the TIPs subfamily, NIPs subfamily, and SIPs subfamily. The PIPs subfamily had the largest genes, which were due to tandem repeats of some genes with similar structures on the chromosome. Among the four subfamilies, the PIPs subfamily contained seven pairs of tandem repeats genes, while only one tandem repeat gene in the NIPs and SIPs subfamilies (Table 3).

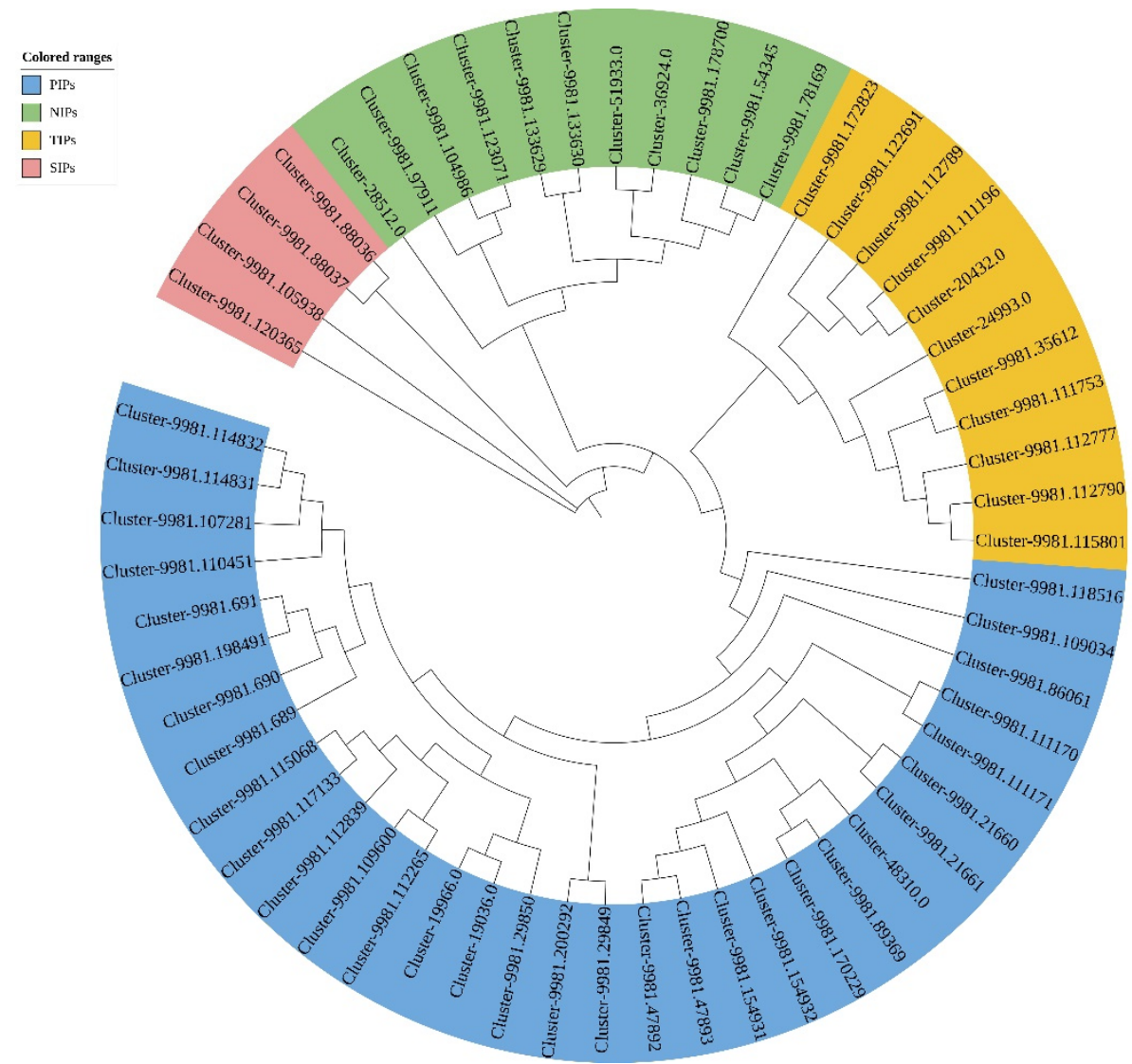

Figure 2. Phylogenetic analysis of the LvAQP gene family. 
Table 3. Tandem repeats genes in the LvAQP gene family.

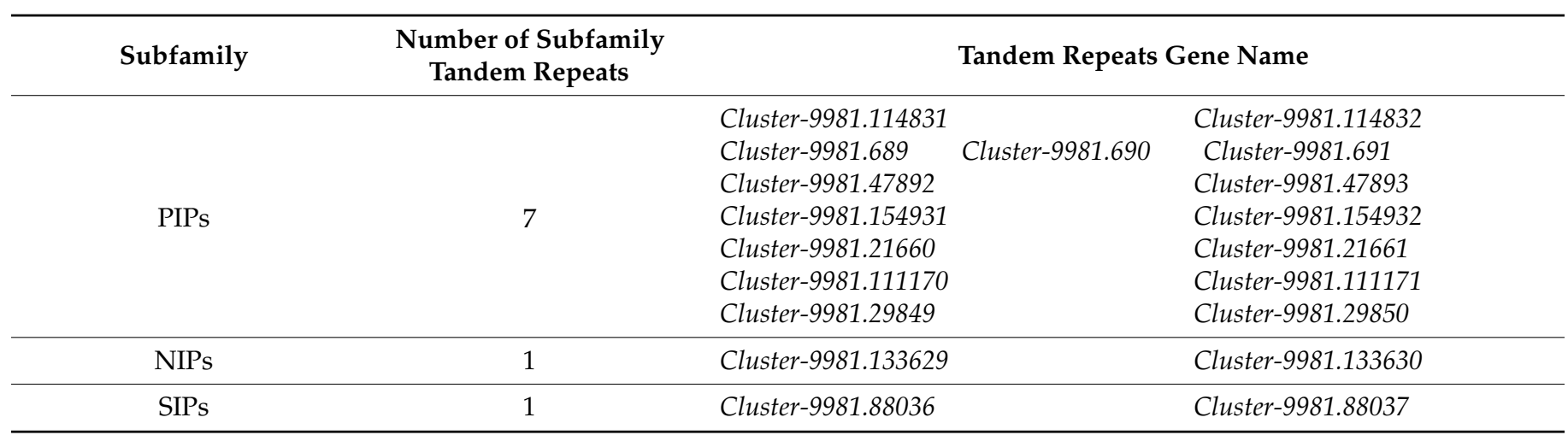

Comparing the aquaporin gene family of Monocotyledonous Oryza sativa, Zea mays and Musa acuminata, and dicotyledonous Arabidopsis thaliana and Brassica rapa with that of Ligustrum $\times$ vicary, the results showed that the number of the PIPs gene subfamily was the largest, while the number of the SIPs gene subfamily was the smallest (Table 4). Furthermore, the distribution of the four gene subfamilies of the LvAQP gene family was generally the same as that of the subfamily members of other plants. Ligustrum $\times$ vicaryi is a dicotyledonous plant. Unlike other plants, in Ligustrum $\times$ vicaryi, the number of aquaporin genes in the PIPs subfamily was nearly two times higher than that of TIPs subfamily and NIPs subfamily, while it was similar to that of the TIPs and NIPs subfamilies in other plants. PIPs located on the plasma membrane were highly selective to the transport matrix, and they are critical for maintaining the water balance of cells in plants [39]. Thus, it isspeculated that the Ligustrum $\times$ vicaryi PIPs subfamily (LvPIPs) may play a major role in maintaining its own water balance of cells.

Table 4. Distribution of subfamily members of the AQP gene family in various plants.

\begin{tabular}{|c|c|c|c|c|c|}
\hline Plants & PIPs & TIPs & NIPs & SIPs & Total \\
\hline Arabidopsis thaliana & 13 & 10 & 9 & 3 & 35 \\
\hline Oryza sativa & 11 & 10 & 10 & 2 & 33 \\
\hline Zea mays & 13 & 11 & 4 & 3 & 31 \\
\hline Brassica rapa & 22 & 16 & 15 & 6 & 59 \\
\hline Musa acuminata & 18 & 17 & 9 & 3 & 47 \\
\hline Ligustrum $\times$ vicaryi & 32 & 11 & 11 & 4 & 58 \\
\hline
\end{tabular}

In this study, a phylogenetic tree was constructed based on 35 Arabidopsis thaliana aquaporin genes, 35 Oryza sativa aquaporin genes, 58 candidate LvAQP genes and aquaporin genes related to cold stress in other plants (Figure 3). Most of the aquaporin genes related to cold resistance were distributed in the PIPs subfamily (Figure 3), while the number of genes of the PIPs subfamily in Arabidopsis thaliana and Oryza sativa were relatively small (Table 4). There was only a pair of tandem repeats genes (At2G37170 and At2G37180) in the PIPs subfamily in Arabidopsis thaliana (Table A1), while there were seven pairs of tandem repeats genes in the LvPIPs subfamily. Therefore, the reason for the large number of LvPIPs may be that genes are relatively tightly distributed on chromosomes, and tandem duplication led to gene amplification. 


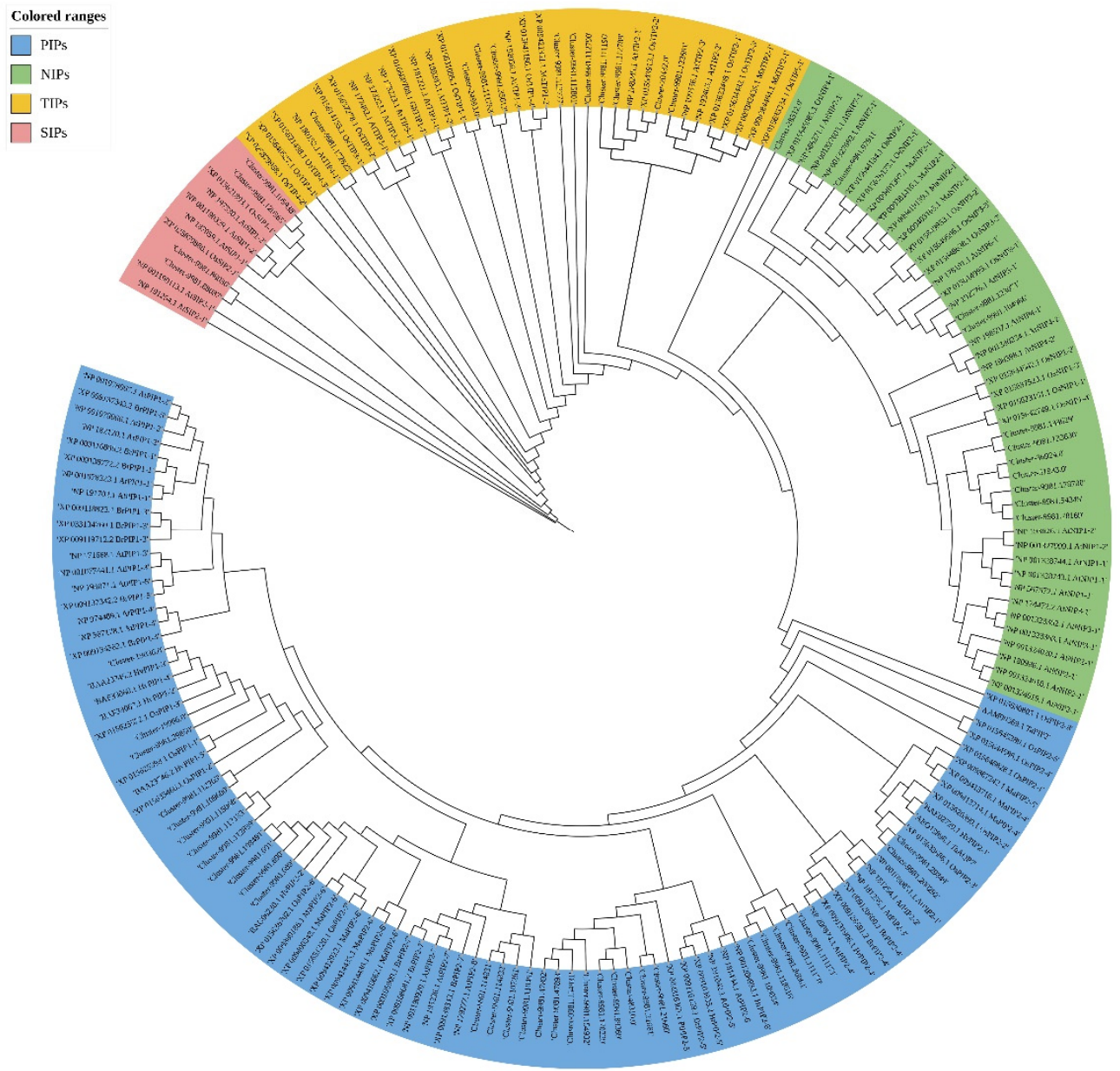

Figure 3. Phylogenetic analysis of LvAQP genes and cold stress-related aquaporin genes in other plants.

\subsection{LvAQP Gene Family Conserved Motifs Analysis}

The identified LvAQP genes all contained conserved domains. Table 5 showes that the LvAQP gene family containes 19 main conserved motifs. The distribution of 58 LvAQP conservative motifs isshown in Figure 4, and the four subfamilies share common conservative motifs, such as motif1. Each subfamily has similar conserved sites, and the members of each subfamily contain similar conserved motifs, even the same, such as Cluster-9981.115068 and Cluster-9981.109600 of the PIPs subfamily. Each subfamily contains its own unique motifs. For example, all members of the PIPs subfamily contain motif 3 , motif 4 , motif 5 , and motif 11 . All members of the TIPs subfamily contain motif 7 and motif 19 . All members of the NIPs subfamily contain motif 12 , motif 14 , and motif 15 . The connected motif 17 and motif 1 are in the SIPs subfamily. Each LvAQP subfamily was highly conserved during the process of evolution, which was beneficial to the phylogeny of the LvAQP gene family. 
Table 5. The 19 conserved motif information of LvAQP genes.

\begin{tabular}{|c|c|c|c|c|}
\hline Motif Type & Motif Sequences & Sites & Width & E-Value \\
\hline Motif 1 & KRSARDSHVPVLAPLPIGFAVFMVHLATIPITGTGINPARSFGAAVIYNK & 54 & 50 & $7.7 \mathrm{e}-1602$ \\
\hline Motif 2 & VYCTAGISGGHINPAVTFGLFLARKVSLIRAIMYIVAQCLGAICGVGLVK & 50 & 50 & $2.5 e-1531$ \\
\hline Motif 3 & KDYKDPPPAPLFDAGELKKWSFYRALIAEFIATLLFLYITVLTVIGYKSQ & 28 & 50 & $9.2 \mathrm{e}-1070$ \\
\hline Motif 4 & YQKYGGGANELADGYSKGTGLGAEIIGTFVLVYTVFSATDP & 32 & 41 & $6.3 e-911$ \\
\hline Motif 5 & KAWDDHWIFWVGPFIGAAIAAFYHQYILR & 26 & 29 & $4.3 e-568$ \\
\hline Motif 6 & DKCGGVGILGIAWAFGGMIFV & 35 & 21 & $2.1 \mathrm{e}-374$ \\
\hline Motif 7 & KAALAEFISTLIFVFAGEGSGMAYNKLTGBAPLTPAGLVAAAVAHAFALF & 9 & 50 & $2.8 \mathrm{e}-167$ \\
\hline Motif 8 & KGIWVYWVGPLIGAGLAAWVY & 25 & 21 & $5.9 \mathrm{e}-162$ \\
\hline Motif 9 & SDWZALVVEIIITFGLVFTVY & 22 & 21 & $3.0 \mathrm{e}-168$ \\
\hline Motif 10 & AMENKEEDVRLGANKYSERQPJGTAAQSD & 8 & 29 & $3.4 \mathrm{e}-125$ \\
\hline Motif 11 & AIKALGSFRSS & 19 & 11 & $2.1 \mathrm{e}-090$ \\
\hline Motif 12 & KHGNSSGCSLLTLSFIQKIIAEILGTYFLIFAGCAAVVVNA & 8 & 41 & $5.2 \mathrm{e}-079$ \\
\hline Motif 13 & MAKDVEEEPEG & 19 & 11 & $6.4 \mathrm{e}-049$ \\
\hline Motif 14 & NIIRFTDKPLREITKS & 6 & 16 & $2.2 \mathrm{e}-045$ \\
\hline Motif 15 & LLFTGKHDHFSGTLP & 7 & 15 & $5.0 \mathrm{e}-037$ \\
\hline Motif 16 & AFQKSY & 24 & 6 & $2.3 e-035$ \\
\hline Motif 17 & TPVIPAPYPDILRGPSLNVDLKSGALAEGLLTFAITF & 6 & 37 & $2.3 e-027$ \\
\hline Motif 18 & LRQQGHIFNPSJPKPSHKAPNAFLLNRSRPPKSRFLFDSVQ & 4 & 47 & $1.2 \mathrm{e}-025$ \\
\hline Motif 19 & FFINHSHEPLPSSEY & 7 & 15 & $1.7 \mathrm{e}-019$ \\
\hline
\end{tabular}

Motif sequences represent the motif consensus in this experiment. Sites stand for the number of occurrences of this motif in 58 LvAQP genes. Width represents the width of the motif. E-value represents the statistical significance of the motif. The smaller the E-value, the more reliable the result.
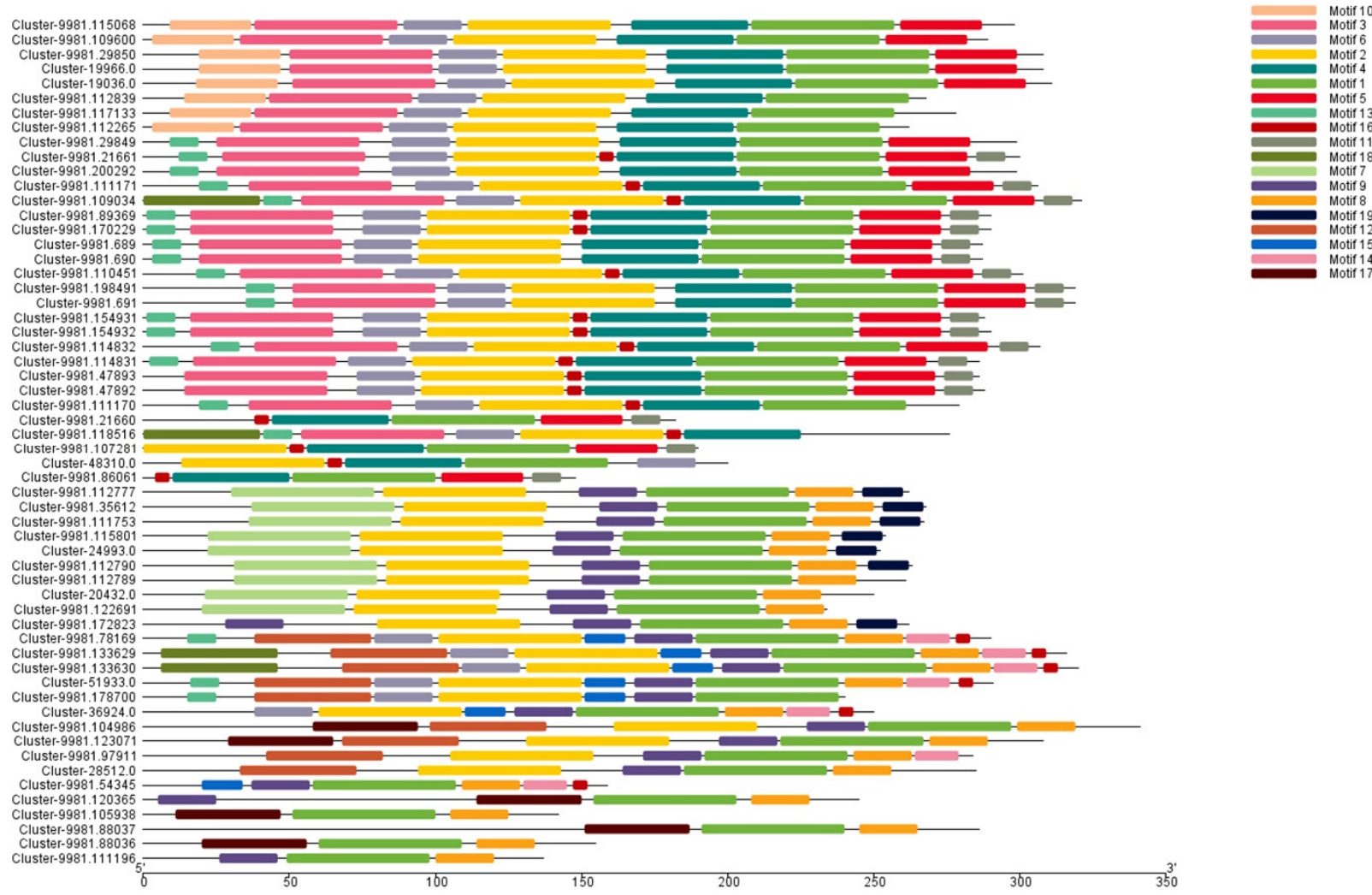

Figure 4. Conserved motif distribution map of LvAQP genes.

All the known aquaporin genes related to cold stress contain several common gene sequence fragments (Figure 5), namely IAEFXXT, GIAW, GGMI, LVYCTAG, SGGHINPAVT, GTFVLVYTVF and ATD, which may play a key role in resisting cold. The above fragments in LvAQP came from motif 2 , motif 3 , motif 4 , and motif 6 . Most of these motifs were dis- 
tributed in the PIPs subfamily of LvAQP. Therefore, the PIPs subfamily might be important for Ligustrum $\times$ vicaryi under cold stress.

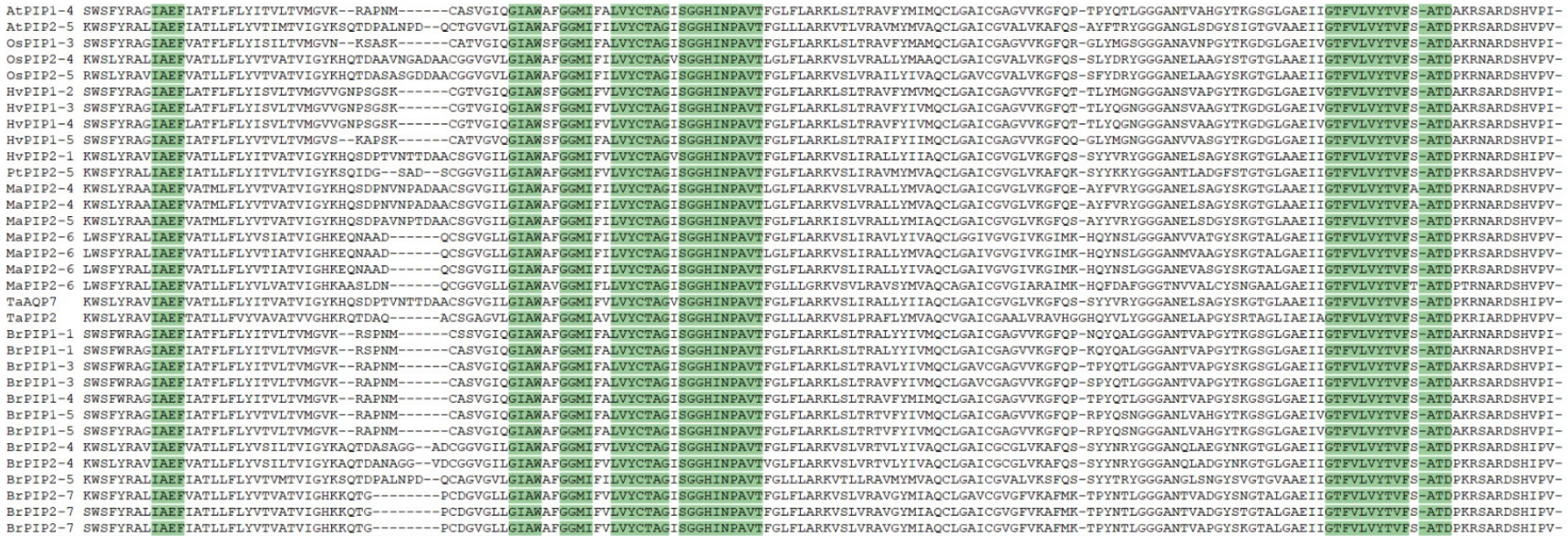

Figure 5. Special gene sequence fragments of aquaporins related to cold stress in plants.

\subsection{Analysis of LvAQP Gene Expression Pattern}

The transcript abundance of LvAQP was analyzed in four sampling times, and combining the phylogenetic relationship between cold stress aquaporin genes of various plants and of LvAQP genes (Figure 3) was helpful in identifying the specific expression patterns of individual genes of the LvAQP gene family.

The expression of 58 LvAQP genes changed in September, November, January and April (Figure 6). Transcriptional analysis showed that the PIPs subfamily and TIPs subfamily contained a relatively high expression in four sampling times. Compared to September, $8 \%$ of LvAQP gene expression increased in November and January and decreased in April; $21 \%$ of LvAQP gene expression decreased in November and January and increased in April; $24 \%$ of LvAQP gene expression increased in November, decreased in January, and increased in April; 17\% of LvAQP gene expression decreased in November, increased in January, and decreased in April; 21\% of LvAQP gene expression increased in November and decreased in January and April; 3.4\% of LvAQP gene expression decreased in November and increased in January and April; and 5\% of LvAQP gene expression decreased consecutively in November, January, and April. According to relevant research, the overexpression of MusaPIP1;2 in Musa acuminata enhanced plant freezing resistance [40]; in Arabidopsis thaliana, the overexpression of AtPIP1;4 and AtPIP2;5, along with repressed expression of other PIPs family members enhanced plant cold resistance [25]; in Oryza sativa, there was increased expression of OsPIP2;5 and OsPIP2;7 and decreased expression of OsPIP1;3, which helped to improve cold resistance $[28,41]$. Studies had shown that plants enhance cold resistance by overexpressing or inhibiting the expression of aquaporin genes under cold stress. Therefore, in this study, the researchers selected LvAQP genes, whose gene expression increased in November and January and decreased in April, and whose gene expression decreased in November and January and increased in April in four sampling times, as the target genes. 


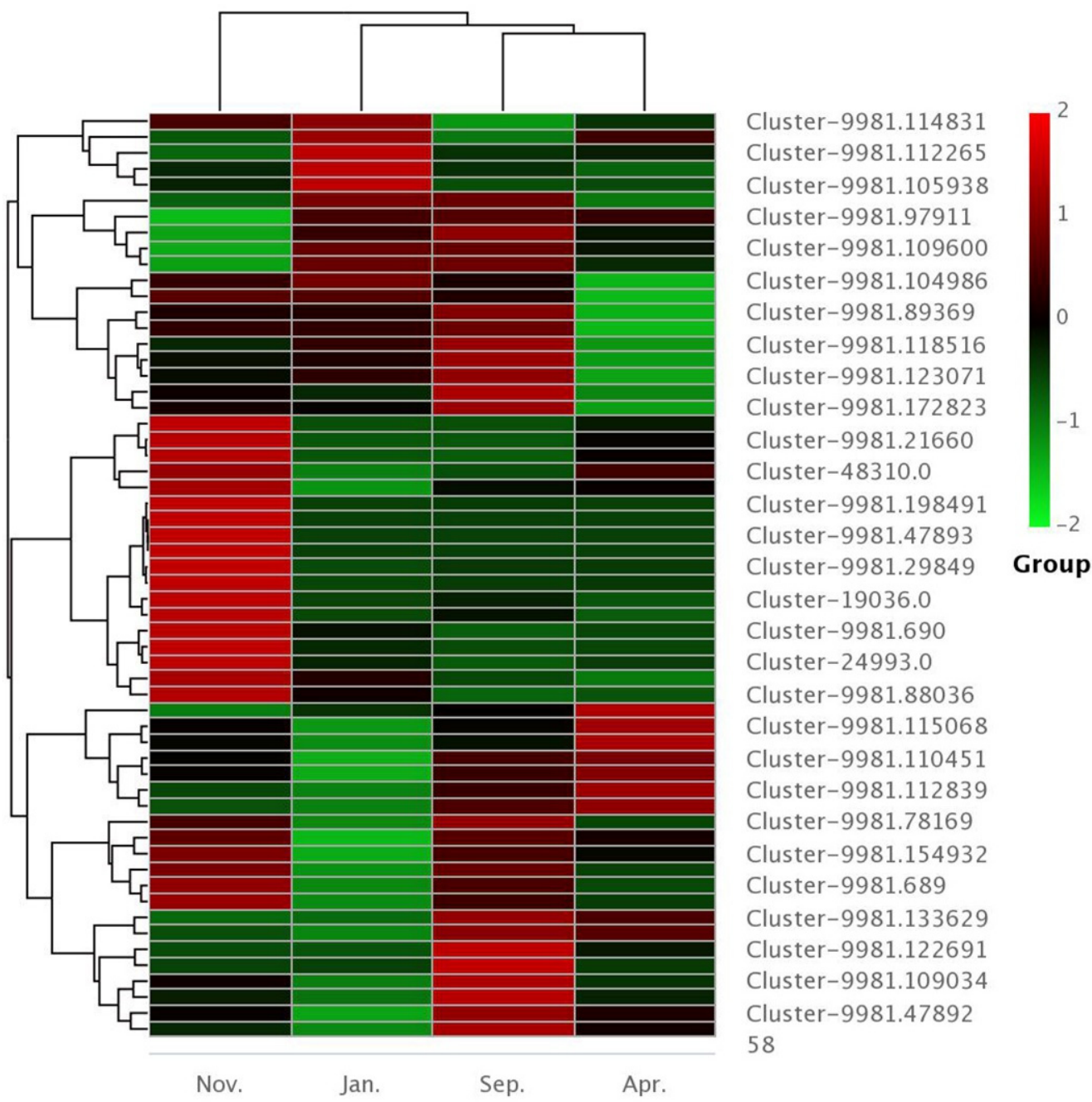

Figure 6. Relative transcript abundance profiles of LvAQP genes during a natural cold stress period.

By analyzing the relative transcript abundance profile of LvAQP genes (Figure 6) and the phylogenetic relationship between cold stress aquaporin genes of various plants and LvAQP genes (Figure 3), 20 LvAQP genes that responded to cold stress were determined: Cluster-9981.109600, Cluster-9981.112839, Cluster-9981.112265, Cluster-9981.111171, Cluster-9981.109034, Cluster-9981.89369, Cluster-9981.110451, Cluster-9981.114832, Cluster9981.114831, Cluster-9981.107281, Cluster-9981.86061, Cluster-9981.112777, Cluster-9981.111753, Cluster-9981.115801, Cluster-9981.112789, Cluster-9981.122691, Cluster-9981.104986, Cluster9981.123071, Cluster-9981.120365 and Cluster-9981.8803. Among the determined 20 LvAQP genes, 11 genes were part of the PIPs subfamily, fivegenes were part of the TIPs subfamily, and two genes were part of the NIPs subfamily and SIPs subfamily, separately.

Among the 20 LvAQP genes identified in response to cold stress, the expression of Cluster-9981.114831 was significantly up-regulated during the two periods of lowest natural temperature in November and January and the most cold-resistant period in January, while the expression of three genes was significantly downregulated, namely, Cluster-9981.112839, Cluster-9981.107281 and Cluster-9981.112777. All the significantly upregulated genes contained motif 6 , and all the significantly downregulated genes contained motif 1 and motif 2 , which were basically consistent with the common special motifs reported in aquaporin genes related to cold stress. It was speculated that the key role of some AQP genes in Ligustrum $\times$ vicaryi for cold resistance might respond to the presence of these specific modular motifs. 


\subsection{KEGG Enrichment Analysis of Differentially Expressed Genes}

KEGG pathway enrichment analysis of differentially expressed genes was conducted under natural cold stress in Ligustrum $\times$ vicaryi (Table 6). A total of 12,872 differentially expressed genes were distributed in 338 pathways, and 10 of them showed significant differences $(p<0.05)$. The differentially expressed genes were significantly enriched in ribosome (ko03010), starch and sucrose metabolism (ko00500), plant hormone signal transduction (ko04075).

Table 6. KEGG pathway enrichment analysis in DEGs of Ligustrum $\times$ vicaryi.

\begin{tabular}{cccc}
\hline Pathway ID & Pathway & $p$ Value & Gene Number \\
\hline ko03010 & Ribosome & $1.51 \mathrm{E}-07$ & 448 \\
ko00940 & Phenylpropanoid biosynthesis & $1.18 \mathrm{E}-06$ & 131 \\
ko00460 & Cyanoamino acid metabolism & $5.77 \mathrm{E}-06$ & 85 \\
ko00500 & Starch and sucrose metabolism & $8.38 \mathrm{E}-05$ & 208 \\
ko04075 & Plant hormone signal transduction & 170 \\
ko05322 & Systemic lupus erythematosus & $7.11 \mathrm{E}-03$ & 48 \\
ko05034 & Alcoholism & $8.15 \mathrm{E}-03$ & 87 \\
ko04915 & Estrogen signaling pathway & 68 \\
ko04612 & Antigen processing and presentation & $1.16 \mathrm{E}-02$ & 72 \\
ko00520 & Amino sugar and nucleotide sugar metabolism & $2.38 \mathrm{E}-02$ & $3.49 \mathrm{E}-02$ \\
\end{tabular}

\subsection{Expression Verification of Cold-Responsive LvAQP Target Ggenes}

The nine screened LvAQP genes that target differentially expressed gene were verified by real-time PCR. The qRT-PCR results were first calculated by the $2^{-\triangle \triangle C T}$ method, followed by $\log$ calculation based 2 . The change of $\log _{2}$ multiples for the real-time fluorescence quantification of the nine target genes areshown in Table 7.

Table 7. Fluorescence quantification of nine cold-responsive LvAQP target genes.

\begin{tabular}{cccc}
\hline Gene Name & Types of Aquaporin Genes & \multicolumn{2}{c}{$\log _{2}$ Fold Change } \\
& & RNA-Seq & Real-Time \\
\hline Cluster-9981.109600 & PIPs & -1.8929 & -0.76 \\
Cluster-9981.112839 & PIPs & -1.5391 & -1.18 \\
Cluster-9981.111171 & PIPs & -2.0145 & -0.63 \\
Cluster-9981.109034 & PIPs & -2.2498 & -2.82 \\
Cluster-9981.114831 & PIPs & 2.5535 & 2.86 \\
Cluster-9981.107281 & PIPs & -3.7174 & -0.79 \\
Cluster-9981.112777 & TIPs & -3.4918 & -4.25 \\
Cluster-9981.115801 & TIPs & -1.9979 & -0.38 \\
Cluster-9981.122691 & TIPs & -4.1174 & -3.16 \\
\hline
\end{tabular}

Although the real-time PCR results of individual genes deviated from the RNA-Seq results in terms of differential fold, the up-regulated and down-regulated expression trends between them were consistent (Figure 7). In addition, the correlation analysis between the results of the qRT-PCR analysis and RNA-seq sequencing results showed that the correlation coefficient $R^{2}$ reached 0.70 (Figure 8), indicating that the transcriptome sequencing results of Ligustrum $\times$ vicaryi cold resistance were reliable. 


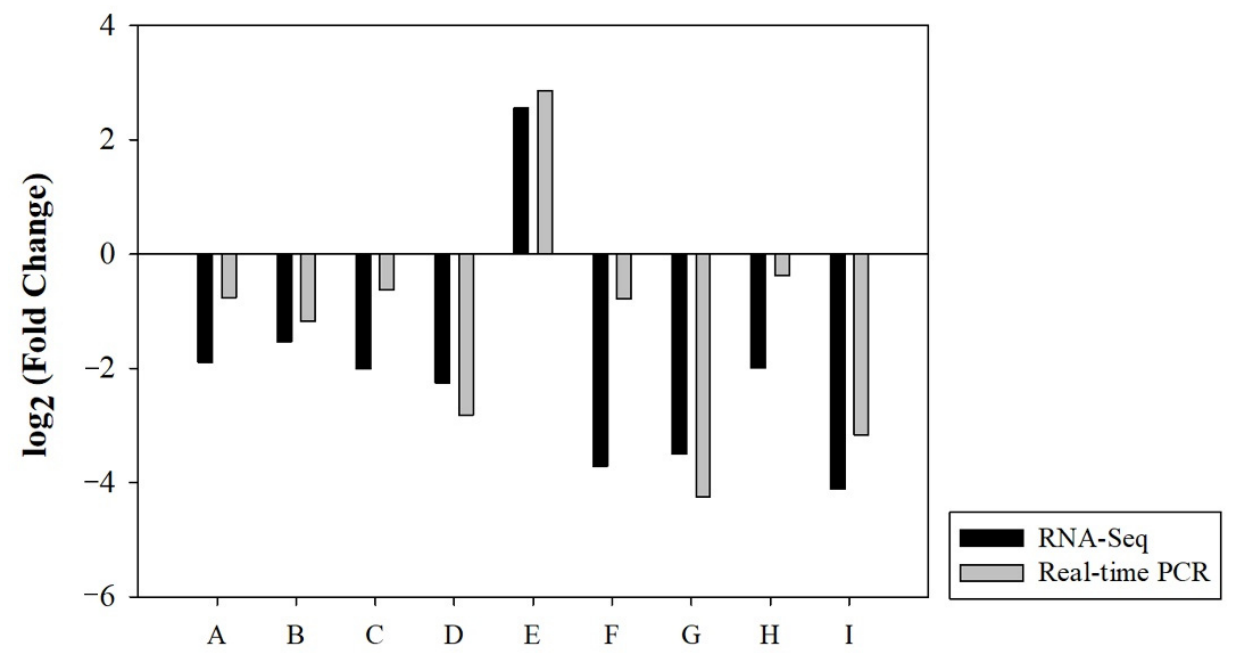

Figure 7. Comparison between RNA-seq and real-time PCR results. A: Cluster-9981.109600; B: Cluster-9981.112839; C: Cluster-9981.111171; D: Cluster-9981.109034; E: Cluster-9981.114831; F: Cluster-9981.107281; G: Cluster-9981.112777; H: Cluster-9981.115801; I: Cluster-9981.122691.

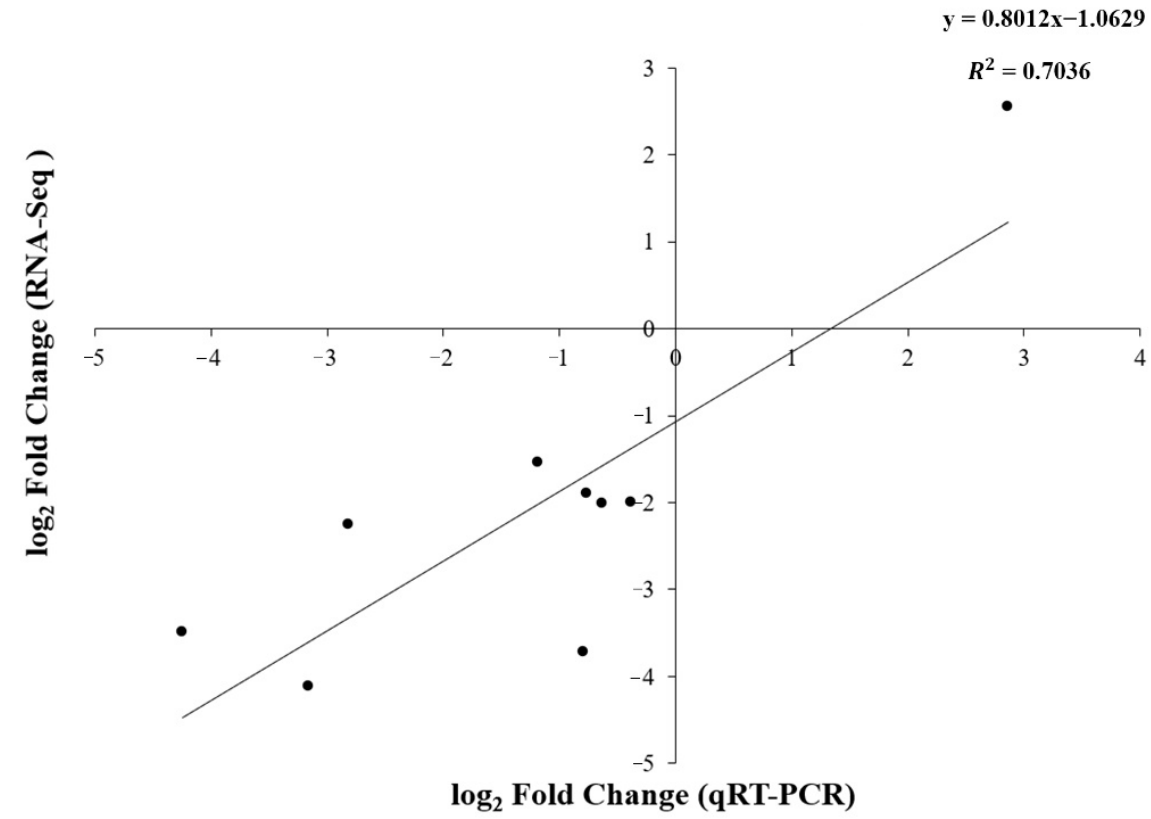

Figure 8. Correlation analysis between RNA-seq and qRT-PCR.

\section{Discussion}

The number of genes encoding aquaporin of Ligustrum $\times$ vicaryi was more than that in Arabidopsis thaliana, especially in the PIPs subfamily due to gene amplification. In this study, 58 candidate LvAQP genes were found. Phylogenetic analysis showed that these 58 LvAQP genes can be divided into four subfamilies: PIPs, TIPs, NIPs and SIPs. A fifth subfamily has also been reported: XIPs, which is a class of atypical non-specific intrinsic aquaporins. It was absent in Arabidopsis thaliana, Oryza sativa, Zea mays and Ligustrum $\times$ vicaryi. Plasma membrane intrinsic proteins are highly selective for the transporting matrix, and they play an important role in maintaining cell water balance under various adversities [15]. Studies have shown that plants resist abiotic stress by regulating the expression and activity of PIPs in the plasma membrane [39,42-44]. Plants mainly regulate their response to stress through the expression or inhibition of PIPs genes of the aquaporin family. Under natural low temperature adversity, maintaining water balance in the body is a considerable challenge to Ligustrum $\times$ vicaryi. At this time, the transmembrane transport of water in 
Ligustrum $\times$ vicaryi mainly depends on the PIPs subfamily of the aquaporin family. This study found that the number of PIPs subfamily was the largest in the LvAQP gene family, which was consistent with the results of previous studies [4-10]. The differences from previous studies were that Arabidopsis thaliana and Oryza sativa have 13 and 11 PIPs genes, respectively, while this study found 32 PIPs subfamily genes in Ligustrum $\times$ vicaryi. The number of genes in the LvPIPs subfamily was much higher than that of other plants. When a certain gene family has obvious gene clusters on the chromosome, it is often accompanied by the gene expansion mechanism of tandem replication [45]. The large number of the PIPs subfamilies of LvAQP gene family was caused by the expansion and tandem duplication of some genes with similar structure in the gene cluster. In this study, the number of LvPIPs genes was higher than that of other plants. There were 11 of the 20 aquaporin genes screened that were related to low temperature stress belonged to the PIPs subfamily. The result of 11 genes belonged to the PIPs subfamily was in accordance with previous studies on aquaporins in response to cold stress, suggesting that the PIPs subfamily of aquaporin might play a major role in responses to cold stress in Ligustrum $\times$ vicaryi $[11,28-30,32,33]$. Unlike in previous studies, two genes of the SIPs subfamily in the LvAQP gene family also responded to cold stress.

In the face of cold stress, plants generally respond to stress by regulating water homeostasis in the body, in which aquaporin proteins are one of the key pathways of water transport [46-49]. The expression patterns of aquaporins in various plant tissues are different, which indicates that aquaporins may have different functions in plants [50]. After freezing treatment, the low-temperature-tolerant Zea mays variety z7 maintained root hydraulic conductivity and water transport by expressing a large amount of aquaporins to reduce freezing damage [51]. The aquaporins PIP1 and PIP2 of Arabidopsis thaliana cooperated synergistically in the roots under cold stress to affect root hydraulic conductivity and to regulate plant cold resistance [52]. Overexpression of PtPIP2;5, PtPIP2;1 and PtPIP2;3 in Populus trichocarpa affected its response to cold stress and osmotic stress [53]. Under cold stress, the overexpression of banana MaPIP2;7 lowered the MDA content and electrolyte leakage in the plant, while the content of chlorophyll, proline, soluble sugar and ABA was higher, thereby enhancing the tolerance to various stresses such as the cold [54]. The overexpression of MaSIP2;1, OsPIP2;7, and TaAQP7 (PIP2) regulated the osmotic balance in plants, reduced membrane damage and oxidation, and adjusted the levels of hormones such as ABA and GA to improve the cold tolerance of plants [30,36,43].

In this study, the phylogenetic comparison between LvAQP genes and reported aquaporin genes related to cold stress in other plants as well as the changes of aquaporin genes transcription abundance in four sampling times was conducted to identify the specific expression patterns of individual genes of the gene family under natural cold stress. The 20 aquaporin genes that responded to cold stress were screened from the 58 LvAQP genes; eleven belonged to the LvPIPs subfamily, five belonged to the LvTIPs subfamily, and two belonged to the LvNIPs subfamily and LvSIPs subfamily, separately, which indicated that genes of the PIPs subfamily played a major role in response to natural cold stress. Among these 20 aquaporin genes of Ligustrum $\times$ vicaryi that responded to cold stress, all the significantly upregulated genes contained motif 6 , while all the significantly downregulated genes contained motif 1 and motif 2 . It was speculated that motif 1 , motif 2 and motif 6 might play an important role in response to cold stress when Ligustrum $\times$ vicaryi is under a natural low temperature. In the analysis of the reported cold stress-related AQP gene sequences of other plants, we found that the gene sequence SGGHINPAVT was present in motif 2 and GIAW and GGMI were present in motif 6; thus, it was further speculated that the gene sequences of SGGHINPAVT, GIAW and GGMI might play a major role in the response to cold stress in Ligustrum $\times$ vicaryi. However, the AEFXXT motif, which was conserved in almost all MIPs in previous studies, was not conserved in all significantly upregulated and significantly downregulated genes in Ligustrum $\times$ vicaryi in response to cold stress. Therefore, we speculated that the AEFXXT motif might not be the key motif in genes responding to cold stress. From the determination of cold resistance of Ligustrum $\times$ vicaryi, 
it can be seen that Ligustrum $\times$ vicaryi was most resistant to cold in January during the natural overwintering process, and the cold resistance of the plant changed with the change of time. In this study, 75\% of the LvAQP genes that were significantly related to cold stress decreased in November and January, and their expression increased in April, which is consistent with the results of transcriptome analysis of Arabidopsis thaliana, Oryza sativa, and the roots and leaves of Zea mays [25,43,51]. In winter, low temperatures can easily lead to freeze thaw embolism of plants, which blocks water transport and leads to withering. At this time, aquaporin may be involved in embolization repair. Low soil temperature limits the absorption of water by roots, leading to a water imbalance. Low soil temperature can reduce or increase the activity of aquaporin in roots, but appropriate low temperature acclimation can promote the abundance of AQP in roots. In the process of natural cold stress, with the enhancement of cold resistance, Ligustrum $\times$ vicaryi regulated the decrease or increase in the expression of aquaporin genes and the corresponding protein activity, and adjusted root hydraulic conductivity, thus maintaining the water balance in the plant, resisting the effects of natural low-temperature stress, and ensuring normal life activities.

Aquaporins are important membrane functional proteins in many physiological reactions, which play a key role mainly through transcriptional regulation, post-translational modification and subcellular localization [55,56]. Plasma membrane intrinsic proteins and tonoplast intrinsic proteins are located on the inner chloroplast membrane and thylakoid membrane [3]. KEGG enrichment analysis of Ligustrum $\times$ vicaryi genes showed that they responded to cold stress mainly through the sucrose metabolism pathway and plant hormone signal transduction pathway. It was speculated that some genes of the PIPs and TIPs subfamilies on the plasma membrane and in the chloroplast were upregulated or downregulated, which would enhance the cold resistance of Ligustrum $\times$ vicaryi by regulating the synthesis and transformation of soluble sugar or starch. After feeling a natural low temperature, differentially expressed genes related to hormone signaling were enriched, and pathways such as ABA signaling were turned on under low temperature stress, thus inducing the expression of downstream regulatory genes. Then, the expression of AQP genes changed in order to regulate the synthesis of corresponding proteins and other macromolecules, to stabilize the membrane structure, and to reduce the water transport rate to avoid low temperature damage of Ligustrum $\times$ vicaryi.

\section{Conclusions}

In this research, the gene expression of LvAQP under natural cold stress was studied. We identified 58 candidate LvAQP genes. Based on phylogenetic analysis, the 58 candidate LvAQP genes were divided into four subfamilies: 32 belonged to the PIPs subfamily, 11 belonged to the TIPs subfamily, 11 belonged to the NIPs subfamily and 4 belonged to the SIPs subfamily. The number of genes in the PIPs subfamily was nearly twice as large as that in other plants. The LvAQP gene family contained nine pairs of tandem repeats genes, which had high conservatism in the process of evolution by searching for conserved motifs. We obtained 20 differentially expressed LvAQP genes under natural cold stress. Among the 20 differentially expressed genes, 11 belonged to the LvPIPs subfamily. Among the 20 differentially expressed genes, the significantly up-regulated gene was Cluster-9981.114831; the significantly down-regulated genes were Cluster-9981.112839, Cluster-9981.107281 and Cluster-9981.112777. These four LvAQP genes might play important roles in response to low temperature stress. The results laid the foundation for further exploration of cold resistant aquaporin genes and biological function verification of Ligustrum $\times$ vicaryi.

Supplementary Materials: The following are available online at https://www.mdpi.com/article/10.3390/ f13020182/s1, Table S1: The genes and primers used for qRT-PCR analysis.

Author Contributions: J.D., S.N., J.Q. and B.D. designed the experiments, J.D., S.N., J.Q., J.Z., M.Z. and Y.M. performed the experiments and collected the data. J.D., S.N., J.Q., J.Z. and M.Z. analyzed 
the data. J.D. wrote the manuscript. S.N., J.Q. and B.D. revised the manuscript. All authors have read and agreed to the published version of the manuscript.

Funding: This research was supported by the Science and Technology Development Center Project of National Forestry and Grassland Administration (KJZXSA202036) and Financial Aid Project for the Introduction of Overseas Students in Hebei Province (CN201711).

Acknowledgments: We would like to thank Huan Sun for her help in the details of the experiment, and Lanbo Wei and Wenjia Shi for their extensive participation in the experiment.

Conflicts of Interest: All the authors declare no conflict of interest.

\section{Abbreviations}

MIPs: major intrinsic proteins; LvAQP: Ligustrum $\times$ vicaryi aquaporins; PIPs: plasma membrane intrinsic proteins; TIPs: tonoplast intrinsic proteins; NIPs: nodulin26-like intrinsic proteins; SIPs: small basic intrinsic proteins; XIPs: uncharacterized $\mathrm{X}$ intrinsic proteins; TMM: trimmed mean of M-values; qRT-PCR: quantitative real-time PCR; LvPIPs: Ligustrum $\times$ vicaryi plasma membrane intrinsic proteins; LvTIPs: Ligustrum $\times$ vicaryi tonoplast intrinsic proteins; LvNIPs: Ligustrum $\times$ vicaryi nodulin26-like intrinsic proteins; LvSIPs: Ligustrum $\times$ vicaryi small basic intrinsic proteins; REL: relative electrolyte leakage.

\section{Appendix A}

Table A1. List of 35 Aquaporins of Arabidopsis thaliana.

\begin{tabular}{|c|c|c|c|}
\hline Subfamily & Name & Synonyms & NCBI Reference Sequence \\
\hline \multirow{13}{*}{ PIPs } & PIP1;1 & PIP1A & AT3G61430 \\
\hline & PIP1;2 & PIP1B; TMPA & AT2G45960 \\
\hline & PIP1;3 & PIP1C; TMPB & AT1G01620 \\
\hline & PIP1;4 & TMPC & AT4G00430 \\
\hline & PIP1;5 & PIP1D & AT4G23400 \\
\hline & PIP2;1 & PIP2A & AT3G53420 \\
\hline & PIP2;2 & PIP2B; TMB2B & AT2G37170 \\
\hline & PIP2;3 & RD28; TMP2C & AT2G37180 \\
\hline & PIP2;4 & PIP2F & AT5G60660 \\
\hline & PIP2;5 & PIP2D & AT3G54820 \\
\hline & PIP2;6 & PIP2E & AT2G39010 \\
\hline & PIP2;7 & PIP3; SIMIP & AT4G35100 \\
\hline & PIP2;8 & PIP3B & AT2G16850 \\
\hline \multirow{10}{*}{ TIPs } & TIP1;1 & GAMMA-TIP & AT2G36830 \\
\hline & TIP1;2 & TIP2 & AT3G26520 \\
\hline & TIP1;3 & GAMMA-TIP1 & AT4G01470 \\
\hline & TIP2;1 & DELTA-TIP & AT3G16240 \\
\hline & TIP2;2 & DELTA-TIP2 & AT4G17340 \\
\hline & TIP2;3 & DELTA-TIP3 & AT5G47450 \\
\hline & TIP3;1 & $\alpha$-TIP & AT1G73190 \\
\hline & TIP3;2 & BETA-TIP & AT1G17810 \\
\hline & TIP4;1 & & AT2G25810 \\
\hline & TIP5;1 & & AT1G17820 \\
\hline \multirow{9}{*}{ NIPs } & NIP1;1 & NLM1 & AT4G19030 \\
\hline & NIP1;2 & NLM2 & AT4G18910 \\
\hline & NIP $2 ; 1$ & & AT2G34390 \\
\hline & NIP3;1 & & AT1G31885 \\
\hline & NIP $4 ; 1$ & & AT5G37810 \\
\hline & NIP4;2 & & AT5G37820 \\
\hline & NIP5;1 & & AT4G10380 \\
\hline & NIP6;1 & & AT1G80760 \\
\hline & NIP7;1 & & AT3G06100 \\
\hline
\end{tabular}


Table A1. Cont.

\begin{tabular}{|c|c|c|c|}
\hline Subfamily & Name & Synonyms & NCBI Reference Sequence \\
\hline \multirow{3}{*}{ SIPs } & SIP1;1 & SIP1A & AT3G04090 \\
\hline & $S I P 1 ; 2$ & & AT5G18290 \\
\hline & $S I P 2 ; 1$ & & AT3G56950 \\
\hline
\end{tabular}

\section{References}

1. Kapilan, R.; Vaziri, M.; Zwiazek, J.J. Regulation of aquaporins in plants under stress. Biol. Res. 2018, 51, 2227-2236. [CrossRef] [PubMed]

2. Hove, R.M.; Bhave, M. Plant aquaporins with non-aqua functions: Deciphering the signature sequences. Plant Mol. Biol. 2011, 75, 413-430. [CrossRef] [PubMed]

3. Zunaira, A.; Howton, T.; Sun, Y.; Mukhtar, M.S. The Roles of Aquaporins in Plant Stress Responses. J. Dev. Biol. 2016, 4, 9. [CrossRef]

4. Quigley, F.; Rosenberg, J.M.; Shachar-Hill, Y.; Bohnert, H.J. From genome to function: The Arabidopsis aquaporins. Genome Biol. 2002, 3, 97-108. [CrossRef]

5. Sakurai, J.; Ishikawa, F.; Yamaguchi, T.; Uemura, M.; Maeshima, M. Identification of 33 rice aquaporin genes and analysis of their expression and function. Plant Cell Physiol. 2005, 46, 1568-1577. [CrossRef] [PubMed]

6. Chaumont, F.; Barrieu, F.; Wojcik, E.; Chrispeels, M.J.; Jung, R. Aquaporins Constitute a Large and Highly Divergent Protein Family in Maize. Plant Physiol. 2001, 125, 1206-1215. [CrossRef]

7. Hove, R.M.; Ziemann, M.; Bhave, M. Identification and Expression Analysis of the Barley (Hordeum vulgare L.) Aquaporin Gene Family. PLOS ONE 2015, 10, e0128025. [CrossRef]

8. Da, Y.Z.; Ali, Z.; Chang, B.W.; Xu, L.; Yi, J.X.; Xu, Z.L.; Liu, X.Q.; He, X.L.; Huang, Y.H.; Ma, H.X.; et al. Genome-Wide Sequence Characterization and Expression Analysis of Major Intrinsic Proteins in Soybean (Glycine max L.). PLoS ONE 2013, 8, e56312. [CrossRef]

9. Park, W.; Scheffler, B.E.; Bauer, P.J.; Campbell, B.T. Identification of the family of aquaporin genes and their expression in upland cotton (Gossypium hirsutum L.). BMC Plant Biol. 2010, 10, 142. [CrossRef]

10. Zhou, Y.; Tao, J.; Ahammed, G.J.; Li, J.; Yang, Y. Genome-wide identification and expression analysis of aquaporin gene family related to abiotic stress in watermelon. Genome 2019, 62, 643-656. [CrossRef]

11. Kayum, M.A.; Park, J.I.; Nath, U.K.; Biswas, M.K.; Kim, H.T.; Nou, I.S. Genome-wide expression profiling of aquaporin genes confer responses to abiotic and biotic stresses in Brassica rapa. BMC Plant Biol. 2017, 17, 23. [CrossRef] [PubMed]

12. Song, J.; Ye, G.; Qian, Z.; Ye, Q. Virus-induced plasma membrane aquaporin PsPIP2;1 silencing inhibits plant water transport of Pisum sativum. Bot. Stud. 2016, 57, 1-10. [CrossRef] [PubMed]

13. Gitto, A.; Fricke, W. Zinc treatment of hydroponically grown barley plants causes a reduction in root and cell hydraulic conductivity and isoform-dependent decrease in aquaporin gene expression. Physiol. Plant. 2018, 164, 176-190. [CrossRef] [PubMed]

14. Macho-Rivero, M.A.; Begoa, H.R.M.; Ramona, B.; Schäffner, A.R.; Tanaka, N.; Fujiwara, T.; Gonzalez-Fontez, A.; CamachoCristóbal, J.J.; Camacho-Cristóbal, J.J. Boron Toxicity Reduces Water Transport from Root to Shoot in Arabidopsis Plants. Evidence for a Reduced Transpiration Rate and Expression of Major PIP Aquaporin Genes. Plant Cell Physiol. 2018, 59, 836-844. [CrossRef] [PubMed]

15. Pawłowicz, I.; Rapacz, M.; Perlikowski, D.; Gondek, K.; Kosmala, A. Abiotic stresses influence the transcript abundance of PIP and TIP aquaporins in Festuca species. J. Appl. Genet. 2017, 58, 421-435. [CrossRef]

16. Ayadi, M.; Brini, F.; Masmoudi, K. Overexpression of a Wheat Aquaporin Gene, TdPIP2;1, Enhances Salt and Drought Tolerance in Transgenic Durum Wheat cv. Maali. Int. J. Mol. Sci. 2019, 20, 2389. [CrossRef]

17. Braz, L.; Fernandes, P.D.; Barbosa, D.D.; Dutra, W.F.; Silva, C.R.; Lima, L.M.; Cavalcanti, J.J.V.; Farias, F.J.C.; Santos, R.C. Expression of aquaporin subtypes (GhPIP1;1, GhTIP2;1 and GhSIP1;3) in cotton (Gossypium hirsutum) submitted to salt stress. Agric. Week 2020, 11, 72-84. [CrossRef]

18. Feng, Z.J.; Liu, N.; Zhang, G.W.; Niu, F.G.; Xu, S.C.; Gong, Y.M. Investigation of the AQP Family in Soybean and the Promoter Activity of TIP2;6 in Heat Stress and Hormone Responses. Int. J. Mol. Sci. 2019, 20, 262. [CrossRef]

19. Belanger, G.; Rochette, P.; Castonguay, Y.; Bootsma, A.; Mongrain, D.; Ryan, D.A. Climate change and winter survival of perennial forage crops in eastern Canada. Agron. J. 2002, 94, 1120-1130. [CrossRef]

20. Ogren, E. Effects of climatic warming on cold hardiness of some northern woody plants assessed from simulation experiments. Physiol. Plant. 2001, 112, 71-77. [CrossRef]

21. Lee, S.H.; Singh, A.P.; Chung, G.C. Rapid accumulation of hydrogen peroxide in cucumber roots due to exposure to low temperature appears to mediate decreases in water transport. J. Exp. Bot. 2004, 55, 1733-1741. [CrossRef] [PubMed]

22. Azad, A.K.; Sawa, Y.; Ishikawa, T.; Shibata, H. Phosphorylation of plasma membrane aquaporin regulates temperature dependent opening of tulip petals. Plant Cell Physiol. 2004, 45, 608-617. [CrossRef] [PubMed]

23. Lee, S.H.; Chung, G.C.; Steudle, E. Gating of aquaporins by low temperature in roots of chilling sensitive cucumber and chilling tolerant figleaf gourd. J. Exp. Bot. 2005, 56, 985-995. [CrossRef] [PubMed] 
24. Kuwagata, T.; Ishikawa-Sakurai, J.; Hayashi, H.; Nagasuga, K.; Fukushi, K.; Ahamed, A.; Takasugi, K.; Katsuhara, M.; MuraiHatano, M. Influence of Low Air Humidity and Low Root Temperature on Water Uptake, Growth and Aquaporin Expression in Rice Plants. Plant Cell Physiol. 2012, 53, 1418-1431. [CrossRef]

25. Jang, J.Y. Transgenic Arabidopsis and tobacco plants overexpressing an aquaporin respond differently to various abiotic stresses. Plant Mol. Biol. 2007, 64, 621-632. [CrossRef] [PubMed]

26. Ahamed, A.; Murai-Hatano, M.; Ishikawa-Sakurai, J.; Hayashi, H.; Kawamura, Y.; Uemura, M. Cold stress-induced acclimation in rice is mediated by root-specific aquaporins. Plant Cell Physiol. 2012, 53, 1445-1456. [CrossRef]

27. Xu, C.; Wang, M.; Zhou, L.; Quan, T.; Xia, G. Heterologous Expression of the Wheat Aquaporin Gene TaTIP2;2 Compromises the Abiotic Stress Tolerance of Arabidopsis thaliana. PLoS ONE 2013, 8, e79618. [CrossRef]

28. Matsumoto, T.; Lian, H.L.; Su, W.A.; Tanaka, D.; Liu, C.W.; Iwasaki, I.; Kitagawa, Y. Role of the aquaporin PIP1 subfamily in the chilling tolerance of rice. Plant Cell Physiol. 2009, 50, 216-229. [CrossRef]

29. Duan, R.J.; Xiong, H.Y.; Katsuhara, M. Expression of Root HvPIPs of Barley Seedling under Chilling Stress. Plant Physiol. J. 2014, 50, 1203-1208. [CrossRef]

30. Xu, Y.; Li, J.; Song, S.; Liu, J.; Hou, X.; Li, Y.; Jin, Z.; Wang, A.; Huang, D.; Xu, Z.; et al. A novel aquaporin gene MaSIP2-1 confers tolerance to drought and cold stresses in transgenic banana. Mol. Breed. 2020, 40, 439-447. [CrossRef]

31. Hu, W.; Hou, X.; Chao, H.; Yan, Y.; Tie, W.; Ding, Z.; Jin, Z.; Wei, Y.; Liu, J.; Miao, H.; et al. Genome-Wide Identification and Expression Analyses of Aquaporin Gene Family during Development and Abiotic Stress in Banana. Int. J. Mol. Sci. 2015, 16, 19728-19751. [CrossRef] [PubMed]

32. He, W.D.; Gao, J.; Dou, T.X.; Shao, X.H.; Bi, F.C.; Sheng, O.; Deng, G.M.; Li, C.Y.; Hu, C.H.; Liu, J.H.; et al. Early Cold-Induced Peroxidases and Aquaporins Are Associated with High Cold Tolerance in Dajiao (Musa spp. 'Dajiao'). Front. Plant Sci. 2018, 9 , 282. [CrossRef] [PubMed]

33. Ranganathan, K.; El Kayal, W.; Cooke, J.E.; Zwiazek, J.J. Responses of hybrid aspen over-expressing a PIP2;5 aquaporin to low root temperature. J. Plant Physiol. 2016, 192, 98-104. [CrossRef] [PubMed]

34. Reddy, P.S.; Sharma, K.K.; Vadez, V. Genome-wide identification and characterization of the aquaporin gene family in Sorghum bicolor (L.). Plant Gene. 2015, 1, 18-28. [CrossRef]

35. Forrest, K.L.; Bhave, M. The PIP and TIP aquaporins in wheat form a large and diverse family with unique gene structures and functionally important features. Funct. Integr. Genom. 2008, 8, 115-133. [CrossRef]

36. Huang, C.; Zhou, S.; Hu, W.; Deng, X.; Wei, S.; Yang, G.; He, G. The Wheat Aquaporin Gene TaAQP7 Confers Tolerance to Cold Stress in Transgenic Tobacco. Z. Naturforschung. C J. Biosci. 2014, 69, 142-148. [CrossRef]

37. Hao, M.Z.; Han, M.H.; Peng, F.R.; Liang, Y.W. Comparison of the Cold-resistance Capabilities of Four Ligustrum Cultivars. Med. Plant 2012, 3, 111-115.

38. Di, B.; Luoranen, J.; Lehto, T.; Himanen, K.; Silvennoinen, M.; Silvennoinen, R.; Repo, T. Biophysical changes in the roots of Scots pine seedlings during cold acclimation and after frost damage. For. Ecol. Manag. 2018, 431, 63-72. [CrossRef]

39. Kumar, K.; Mosa, K.A.; Meselhy, A.G.; Dhankher, O.P. Molecular insights into the plasma membrane intrinsic proteins roles for abiotic stress and metalloids tolerance and transport in plants. Indian J. Plant Physiol. 2018, 23, 721-730. [CrossRef]

40. Sreedharan, S.; Shekhawat, U.; Ganapathi, T.R. Transgenic banana plants overexpressing a native plasma membrane aquaporin MusaPIP1;2 display high tolerance levels to different abiotic stresses. Plant Biotechnol. J. 2013, 11, 942-952. [CrossRef]

41. Li, G.W.; Zhang, M.H.; Cai, W.M.; Sun, W.N.; Su, W.A. Characterization of OsPIP2;7, a water channel protein in rice. Plant Cell Physiol. 2008, 49, 1851-1858. [CrossRef]

42. Wang, X.; Zhang, J.L.; Feng, X.X.; Li, H.J.; Zhang, G.F. The molecular mechanisms of plant plasma membrane intrinsic proteins trafficking and stress response. Yi Chuan Hered. 2017, 39, 293-301. [CrossRef]

43. Yu, X.; Peng, Y.H.; Zhang, M.H.; Shao, Y.J.; Su, W.A.; Tang, Z.C. Water relations and an expression analysis of plasma membrane intrinsic proteins in sensitive and tolerant rice during chilling and recovery. Cell Res. 2006, 16, 599-608. [CrossRef] [PubMed]

44. Jiang, C.; Song, X.; He, H.; Chu, L.; Zhou, H.; Zhao, Y.; Xu, Y.; Zeng, W.; Lin, X.; Lu, M.Z. Genome-wide identification of plasma membrane aquaporin gene family in Populus and functional identification of PIP1;1 involved in osmotic stress. Environ. Exp. Bot. 2020, 179, 104200. [CrossRef]

45. Simes, M.S.; Carvalho, G.G.; Ferreira, S.S.; Hernandes-Lopes, J.; Setta, N.; Cesarino, I. Genome-wide characterization of the laccase gene family in Setaria viridis reveals members potentially involved in lignification. Planta 2020, 251, 46. [CrossRef] [PubMed]

46. Pawłowicz, I.; Masajada, K. Aquaporins as a link between water relations and photosynthetic pathway in abiotic stress tolerance in plants. Gene 2019, 687, 166-172. [CrossRef] [PubMed]

47. Cheng, H.Q.; Ding, Y.E.; Shu, B.; Zou, Y.N.; Wu, Q.S.; Kuča, K. Plant Aquaporin Responses to Mycorrhizal Symbiosis under Abiotic Stress. Int. J. Agric. Biol. 2020, 5, 786-794.

48. Tang, N.; Shahzad, Z.; Lonjon, F.; Loudet, O.; Vailleau, F.; Maurel, C. Natural variation at XND1 impacts root hydraulics and trade-off for stress responses in Arabidopsis. Nat. Commun. 2018, 9, 1321-1358. [CrossRef]

49. Jang, J.Y.; Kim, D.G.; Kim, Y.O.; Kim, J.S.; Kang, H. An Expression Analysis of a Gene Family Encoding Plasma Membrane Aquaporins in Response to Abiotic Stresses in Arabidopsis Thaliana. Plant Mol. Biol. 2004, 54, 713-725. [CrossRef]

50. Yang, S.D.; Guo, D.L.; Pei, M.S.; Liu, H.; Wei, T.; Yu, Y. Identification of Grapevine AQP Family and prediction of transcriptional regulatory network under drought stress. J. Fruit Sci. 2021, 38, 1638-1652. [CrossRef] 
51. Aroca, R.; Amodeo, G.; Fernández-Illescas, S.; Herman, E.M.; Chaumont, F.; Chrispeels, M.J. The Role of Aquaporins and Membrane Damage in Chilling and Hydrogen Peroxide Induced Changes in the Hydraulic Conductance of Maize Roots. Plant Physiol. 2005, 137, 341-353. [CrossRef] [PubMed]

52. Rahman, A.; Kawamura, Y.; Maeshima, M.; Rahman, A.; Uemura, M. Plasma Membrane Aquaporin Members PIPs Act in Concert to Regulate Cold Acclimation and Freezing Tolerance Responses in Arabidopsis thaliana. Plant Cell Physiol. 2020, 61, 787-802. [CrossRef] [PubMed]

53. Ranganathan, K. Over-Expression of PIP2;5 Aquaporin in a Populus tremula $\times$ P. albaclone and its Effects on Plant Responses to Low Root Temperature and Osmotic Stress. Ph.D. Thesis, University of Alberta, Edmonton, AB, Canada, 2015. [CrossRef]

54. Yi, X.; Hu, W.; Liu, J.; Song, S.; Hou, X.; Jia, C.; Li, J.; Miao, H.; Wang, Z.; Tie, W.; et al. An aquaporin gene MaPIP2-7 is involved in tolerance to drought, cold and salt stresses in transgenic banana (Musa acuminata L.). Plant Physiol. Biochem. 2020, 147, 66-76. [CrossRef]

55. Verdoucq, L.; Rodrigues, O.; Martinière, A.; Luu, D.T.; Maurel, C. Plant aquaporins on the move: Reversible phosphorylation, lateral motion and cycling. Curr. Opin. Plant Biol. 2014, 22, 101-107. [CrossRef] [PubMed]

56. Ricardi, M.M.; González, R.M.; Zhong, S.; Domínguez, P.G.; Duffy, T.; Turjanski, P.G.; Salgado Salter, J.D.; Alleva, K.; Carrari, F.; Giovannoni, J.J.; et al. Genome-wide data (ChIP-seq) enabled identification of cell wall-related and aquaporin genes as targets of tomato ASR1, a drought stress-responsive transcription factor. BMC Plant Biol. 2014, 14, 29. [CrossRef] 